Trivent Publishing

(C) The Authors, 2016

Available online at http://trivent-publishing.eu/

Engineering and Industry Series

Volume Power Systems, Energy Markets and Renewable Energy Sources in

\title{
Composite Outdoor High Voltage Insulators in Crete - 37 Years of Experience
}

\author{
Kiriakos Siderakis, ${ }^{1}$ Dionysios Pylarinos, ${ }^{1}$ Ioannis Pellas, ${ }^{1}$ \\ Emmanuel Thalassinakis, ${ }^{1}$ Nikolaos Mavrikakis ${ }^{2}$ \\ ${ }^{1}$ Hellenic Electricity Distribution Network Operator S.A (HEDNO S.A.), Greece \\ ${ }^{2}$ Department of Electrical Engineering, TEI of Crete, Greece \\ katsigiannis@chania.teicrete.gr
}

\begin{abstract}
Power transmission reliability and system integrity are essential requirements in high voltage transmission and distribution networks. Outdoor insulation has a critical role, since the majority of these installations incorporate open air systems and there are many factors able to trigger deterioration mechanisms, which may finally conclude to a system failure. It is important to notice, that although the initial investment for the insulation systems is low in comparison to other types of equipment, an insulation failure may result in considerable costs for the utility. A strategy that is followed by more and more utilities nowadays is the incorporation of composite insulators, in transmission and distribution systems, where the influence of pollution is considerable. In Crete, this action started 37 years ago, experienced intense action; 15 years ago and today the majority of outdoor insulators are composite. This large scale application is presented in this paper, especially with reference to the problems experienced and the testing and maintenance procedures applied.
\end{abstract}

This is an Open Access article distributed in accordance with the Creative Commons Attribution Non Commercial (CC-BY-NC-ND 4.0) license, which permits others to copy or share the article, provided original work is properly cited and that this is not done for commercial purposes. Users may not remix, transform, or build upon the material and may not distribute the modified material (http://creativecommons.org/licenses/by-nc/4.0/) 


\section{Keywords}

Outdoor Insulation; composite materials; large scale application.

\section{Introduction}

Outdoor installations represent today a large part of transmission and distribution grids, mainly due to the lower cost of design, development and construction. Although there are technologies available today, to develop indoor installations (Gas Insulated Substations and Lines), the relevant cost can be only justified by the increased land value experienced in the cities. Therefore, along the improvement of grids that is experienced today, in the direction of intelligence development (Smart Grids), it is necessary to improve also the available infrastructure, to keep up with the requirements of reliability and quality desired. Unfortunately, being outdoor, these systems are exposed to the action of various environmental parameters and mechanisms. Among them, pollution of high voltage insulators is the most severe in many systems worldwide. A problem appears in different forms, depending on the source of pollution and the participating mechanisms such as wetting. However, in all cases, the result is the deterioration of the insulation performance and further the loss of insulating capability, under nominal voltage stress.

The installation of composite insulators is a decision made for many utilities worldwide during the last 10 to 15 years, although they were available in the market since 1970s. This considerable change to the perspective of this solution was the result of studies and investigations revealing the increased levels of pollution performance of these insulators, when compared to the ceramic insulators, traditionally implemented. This advantage comes in combination to the fact that the way the insulation system reacts to the influence of pollution is changed. The traditionally implemented remedies, such as insulator cleaning were in some way in pursuit of the problem and thus required capable manpower to sufficiently correspond to the problem, also an issue for a utility. On the other hand, in the case of composite insulators, the system is ready and responds to the problem, when necessary. The latter gives a considerable advantage for the utility in the terms of reliability and maintenance cost.

Along with the advantages, problems and issues of concern exist in this case also. The ability of composite insulators to successfully respond to the problem of pollution, is strongly correlated to the material formulation, physical and chemical properties, which are quite different from ceramic. The primary difference is the polymeric (organic or inorganic) material structure, which corresponds to molecular bonds of lower strength and therefore the available 
formulations are more susceptive to environmental aging. Consequently, the issue of insulation reliability has been transformed to a more knowledge demanding problem, requiring specialized evaluation techniques. The latter was the motive for the establishment of a cooperation between HEDNO (Hellenic Electricity Distribution Network Operator), the Technological Institute of Crete and the Foundation for Research and Technology-Hellas, aiming to develop an online evaluation technique which could be able to detect insulation degradation focusing on the material formulation (POLYDIAGNO).

\section{The transmission system of Crete}

Crete is the biggest Greek island in the Aegean Sea, located at the south of Greece. It was the first island were a high voltage transmission system was constructed, started at the level of $66 \mathrm{kV}$ in the $1960 \mathrm{~s}$ and moved to $150 \mathrm{kV}$ at the late 1970s. Today there are in service more that $5000 \mathrm{~km}$ of $150 \mathrm{kV}$ transmission lines and $20150 \mathrm{kV} / 20 \mathrm{kV}$ substations, 18 of which outdoor (150kV part). As illustrated in the map of figure 1, the transmission system is deployed along the island coastline, following the social and economic development of the island. As a result, the majority of the high voltage installations are exposed to the influence of the sea and intense pollution problems were experienced especially during the 1980s and 1990s, as illustrated in figure 2a were the pollution related faults, per $100 \mathrm{~km}$ of transmission lines are presented.

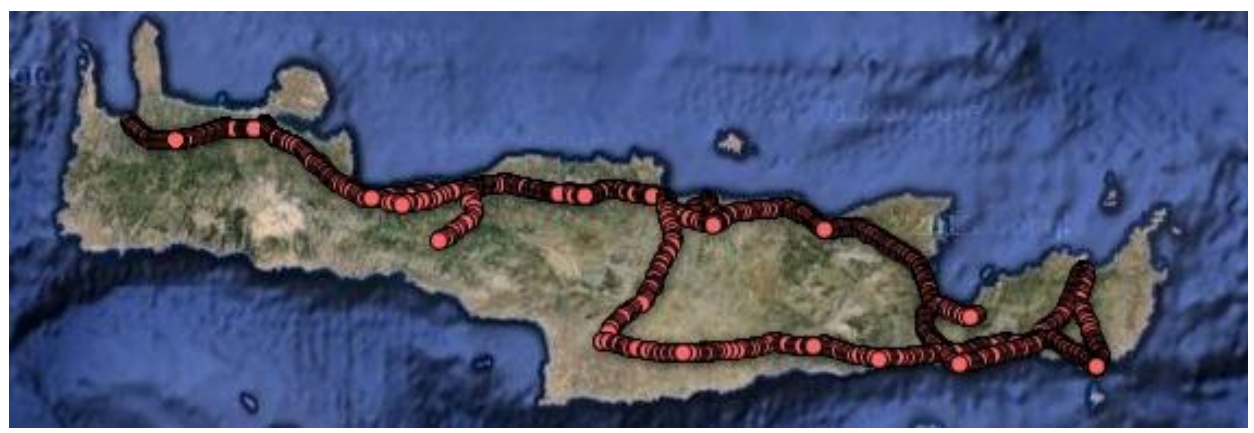

Fig. 1. The 150kV transmission system of Crete

It is evident from figure 2 (blue line) that there is a trend of reduction for the pollution related faults as moving to 2000. It is interesting to combine this graph with the graph demonstrating the number of available linemen (red line) is presented for the same time period. It can be concluded that although the available manpower is considerably reduced the system reliability is increased and maintained in the desired levels for more than 15 years $(2000-2016)$. 


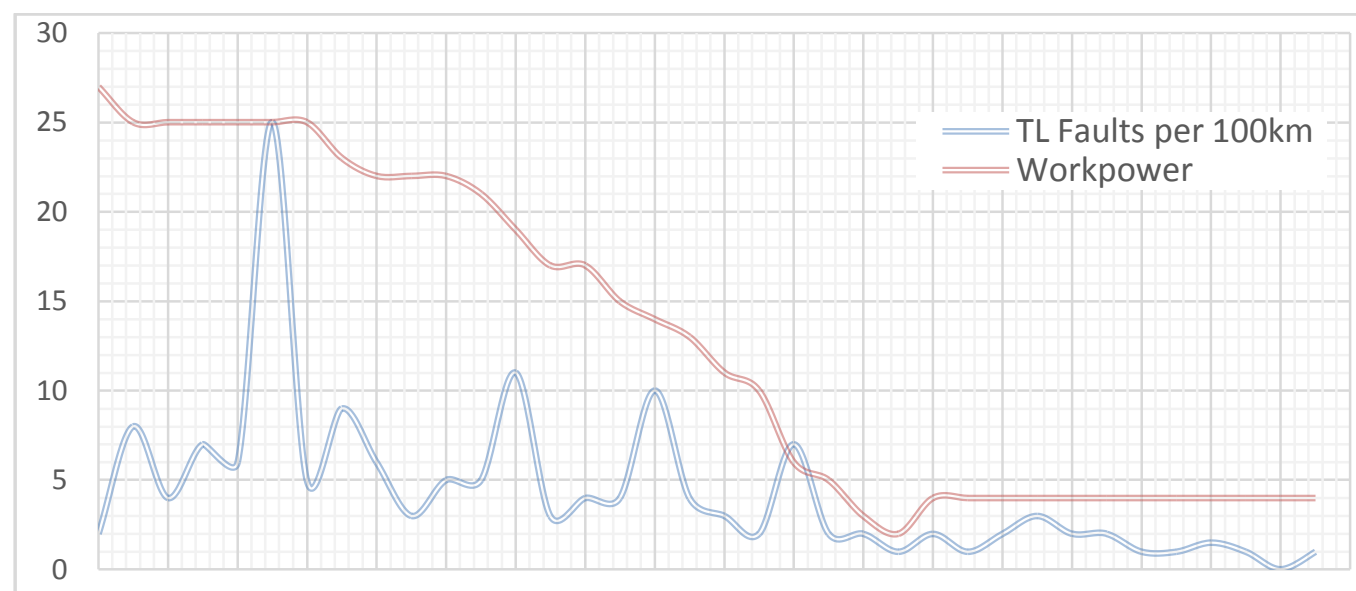

1980198219841986198819901992199419961998200020022004200620082010201220142016

Fig. 2. Pollution related outages per $100 \mathrm{~km}$ fo transmission lines in the $150 \mathrm{kV}$ transmission system of Crete and workpower available for the maintenance

\section{Performance of composite high voltage insulators in Crete}

The first installation of composite high voltage insulators in Crete took place in 1979, were a number of PTFE (Teflon) insulators were installed in one transmission line, located in the north side of the island and a route from the centre to the east side, were the problem of pollution was very intense. The performance of these insulators was exceptional, as far as the problem of pollution is concerned. Throughout the time period, these insulators were in service, no maintenance remedies were taken and no pollution related flashovers were experienced. Unfortunately, they also experienced the problem of brittle fracture, which was very common for composite insulators of the first and second generation. A picture of a Teflon insulator with brittle fracture is illustrated in figure 3. The reason of the problem is known to be the corona discharges experienced and a number of pinholes created as a result. Signs of this degradation have been found in the case of Crete also and a typical example is illustrated in the picture of figure 4. 


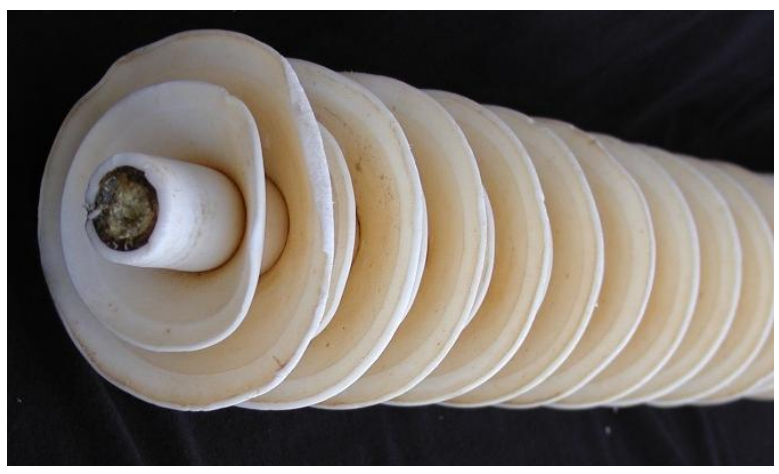

Fig. 3. PTFE insulator destroyed due to the action of brittle fracture

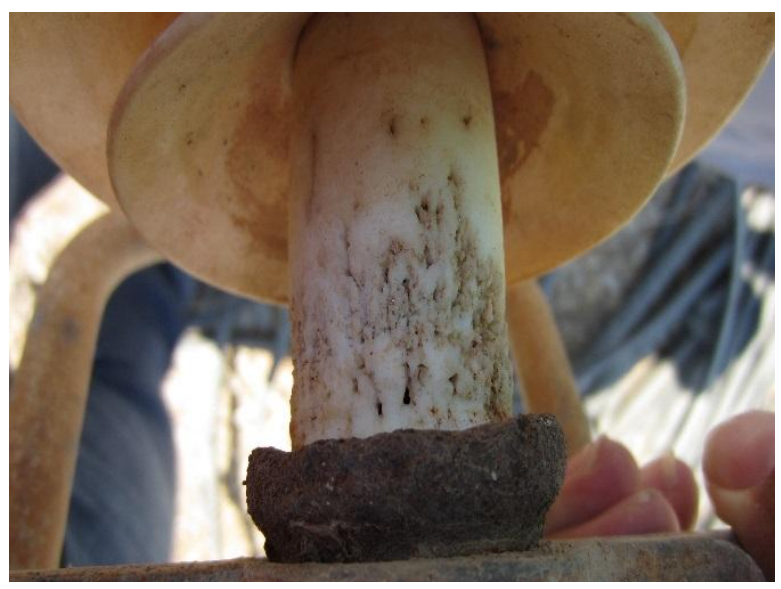

Fig. 4. Pinholes due to corona discharges on a PTFE composite insulator

Twenty one years later, the second stage of composite insulators installation in Crete started. Today 16 years later, the majority of insulators in service in the transmission lines of Crete are composite and the remaining ceramic will be replaced in the near future. The change of the insulation map in Crete is illustrated in the pie graphs of figure 5. 

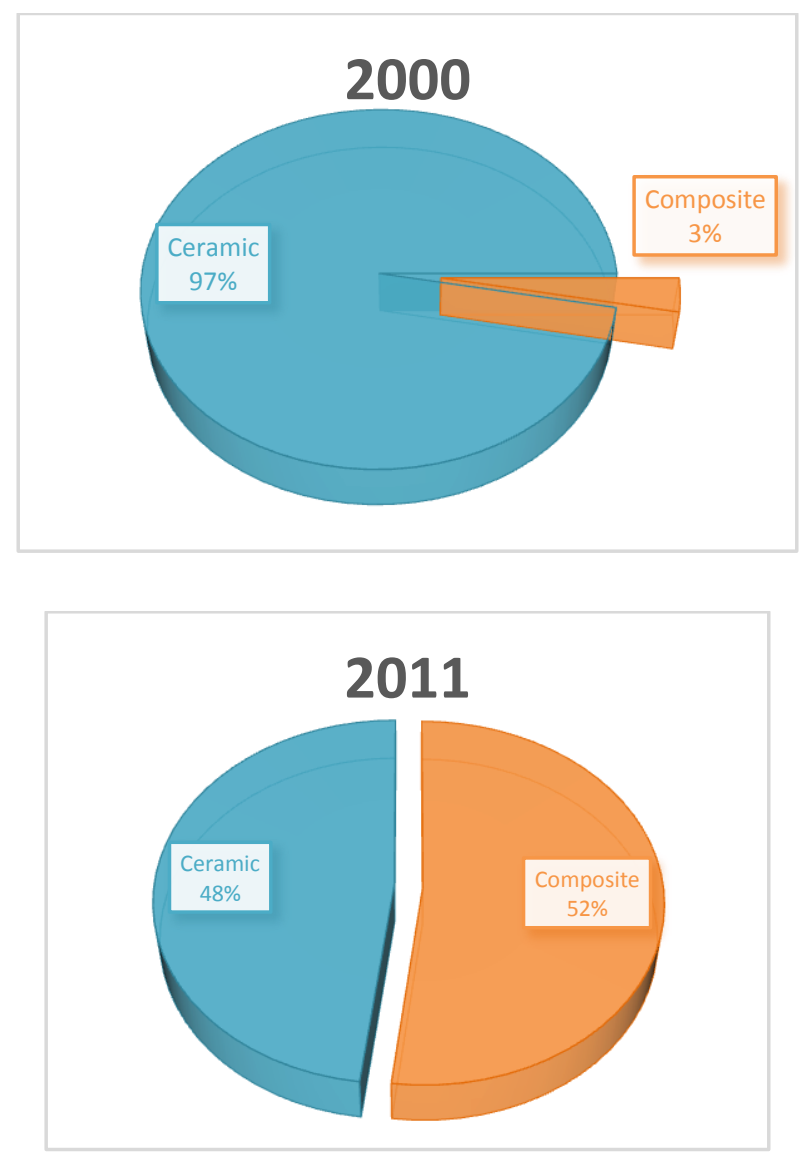

\section{6}

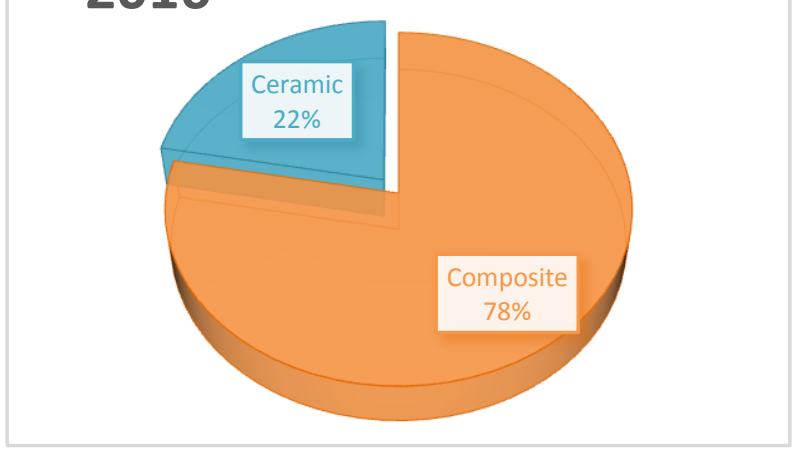

Fig. 5. Insulation map of the $150 \mathrm{kV}$ Transmission lines in Crete in 2000, 2011 and 2016

Since installation, no pollution flashovers have been registered in the $150 \mathrm{kV}$ Transmission lines equipped with composite insulators. The performance and 
reliability achieved is remarkable and throughout a service period of 16 years the application results are beneficial for the system operator both in technical and financial terms. In the same time, the experienced gained from the application of PTFE (TEFLON) insulators, indicates the need for the condition assessment of the insulators material.

\section{Condition assessment of composite high voltage insulators in Crete}

In order to assess the condition of the insulators installed in Crete and considering the large number of units installed, a sampling procedure was decided, based on the insulator age and the pollution stress conditions experienced, according to Equivalent Salt Deposit Density (ESDD) measurements, performed by HEDNO since the 1980s. The insulators selected are included in table 1 . Then the evaluation procedure included laboratory and field electrical aging, with the later performed at TALOS Test Station and a number of physical chemical and material analysis techniques, in order to draw the most possible reliable conclusions about the insulator condition. The evaluation procedure and the tests performed are illustrated in the diagram of figure 6.

Table 1. Sample insulators selected for testing and evaluation

\begin{tabular}{|c|c|c|c|}
\hline $\begin{array}{c}\text { Insulator } \\
\text { Sample } \\
\text { Number }\end{array}$ & Line & Tower & Age (years) \\
\hline 0012 & LM & 6 & 17 \\
\hline 0013 & LM & 47 & 17 \\
\hline 0014 & MI & 201 & 21 \\
\hline 0015 & LCHII & 106 & 17 \\
\hline 0016 & LII & 49 & 10 \\
\hline 0017 & LCHII & 102 & 17 \\
\hline 0018 & LII & 50 & 10 \\
\hline
\end{tabular}




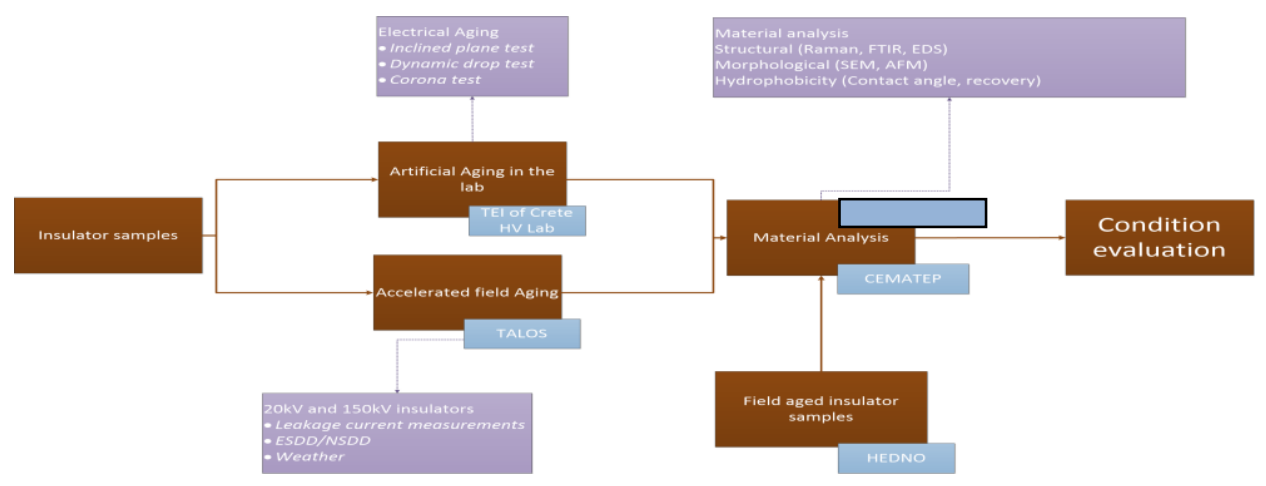

Fig. 6. The insulators evaluation procedure and the tests performed

The test results revealed that although the insulators were in service for many years, the experienced performance is satisfactory, with the exception of certain cases were the base polymer was not Silicone Rubber. In the latter case, the loss of hydrophobicity is evident and certainly an issue of concern. However a very limited number of non-silicone composite insulators has been installed, mainly for testing and evaluation and therefore this is not an issue of concern, since they will be replaced. In the other cases however, although the results are satisfactory, evident of degradation has been detected and therefore further testing is required.

\section{Conclusions}

The application of silicone rubber composite insulators in Crete, can be considered as a successful example of a transmission grid upgrade. However, although no pollution flashovers have been observed, there is an issue of concern for the system operator, regarding the insulation material condition and the efficiency of the application, due to the aging mechanisms present. In this direction a number of samples has been selected from the grid and further evaluated in the laboratory and in the field. The results indicated that after many years of service, the silicone rubber composite insulators, maintain good service performance and efficiency. However, aging defects have been detected and therefore the need for further testing in the future is evident. 


\section{References}

D. Pylarinos, K. Siderakis, E. Thalassinakis, "Comparative Investigation of Silicone Rubber Composite and Room Temperature Vulcanized Coated Glass Insulators Installed in Coastal Overhead Transmission Lines", IEEE Electrical Insulation Magazine, Vol. 31, No. 2, pp. 23-29, 2015

D. Pylarinos, K. Siderakis, E. Thalassinakis, "ESDD Measurements in the power system of Crete", Journal of Electrical Engineering, Vol. 14, No. 4, pp. 172177, 2014 (art. no. 14.4.25)

D. Pylarinos, K. Siderakis, I. Pellas, E. Thalassinakis, "Assessing Pollution of Outdoor Insulators in the Cretan Power System”, 18th International Conference on Circuits, Systems, Communications and Computers (CSCC 2014), Santorini, Greece, July 17-21, 2014.

N. Mavrikakis, K.Siderakis, E. Koudoumas, "Assessment diagnostics of the functionality of composite insulators operating in the $150 \mathrm{kV}$ power network of Crete", 30th Panhellenic Conference on Solid-State Physics and Materials Science, Heraklion, Crete, Greece, 21-24 September, 2014

D. Pylarinos, K. Siderakis, E. Thalassinakis, "R\&D in TALOS High Voltage Test Station-Assessing aging and performance of polymer insulators", 13th International Conference on Circuits, Systems, Electronics, Control \& Signal Processing (CSECS '14), Lisbon, Portugal, October 30-November 1, 2014 D. Pylarinos, K. Siderakis, E. Koudoumas, E. Thalassinakis, "Polymer Insulators and Coatings in the Cretan Power System. The Transmission Line Case", MEDPOWER 9th Mediterranean Conference on Power Generation, Transmission Distribution and Energy Conversion, Athens, Greece, 2-5 November, 2014.

N. Mavrikakis, K. Siderakis, D. Kourasani, M. A. Pechynaki, E. Koudoumas, "Hydrophobicity transfer mechanism evaluation of field aged composite insulators", POWERENG 5th International Conference on Power Engineering, Energy and Electric Drives, Riga, Latvia, May 11-13, 2015

N. Mavrikakis, K. Siderakis, D. Pylarinos, E. Koudoumas, "Assessment of Field Aged Composite Insulators Condition in Crete", DEMSEE 9th International Conference on Deregulated Electricity Market Issues in South Eastern Europe, Nicosia, Cyprus, 25-26 September, 2014 